\title{
Clinical Characteristics and Surgical Management for Juxtafacet Cysts of the Lumbar Spine
}

\author{
Tohru Terao, Hiroshi TAKahashi, Makoto TANiguCHI, Katsuhisa IDE, \\ Munehisa SHINOZAKI, Jyun NAKAUCHI, and Mayumi KUBOTA \\ Department of Neurosurgery, Tokyo Metropolitan Neurological Hospital, \\ Fuchu, Tokyo
}

\begin{abstract}
Retrospective analysis of 10 cases of resection of symptomatic lumbar juxtafacet cysts in nine patients (mean age 65.4 years) investigated the relationship between surgical method and progression of spinal spondylolisthesis or cyst recurrence. Patient characteristics, surgical methods, and postoperative course were reviewed. The most common preoperative symptom, painful radiculopathy, occurred in all cases, followed by motor weakness in five, sensory loss in four, and intermittent claudication in four. All patients underwent bilateral total $(n=6)$ or partial laminectomy $(n=4)$, with minimal $(n=3)$ or no $(n=7)$ facetectomy. Cysts were gross totally resected in eight cases and partially resected in two. Concomitant fixation was not performed. Painful radiculopathy, motor weakness, and sensory disturbance all resolved, resulting in good or excellent outcome in all patients. Postoperative symptomatic spondylolisthesis had not been noted at mean 52.1 months postoperatively. However, new juxtafacet cysts were later detected on the contralateral side to the initial lesion in two patients. Surgical removal of juxtafacet cysts is recommended for immediate symptomatic relief. Concomitant spinal fixation to prevent progression of spinal spondylolisthesis or cyst recurrence depends on cyst size, involvement of surrounding structures, degree of preoperative spondylolisthesis, and facet joint destruction.
\end{abstract}

Key words: juxtafacet cyst, synovial cyst, lumbar spine, spinal spondylolisthesis, spinal fixation

\section{Introduction}

The term "juxtafacet cyst" was first used in 1974 to describe ganglion and synovial cysts within the epidural cavity. ${ }^{23)}$ Neuroimaging advances are detecting juxtafacet cysts with increasing frequency. $6,10,11,13,17,19,22,24-26,29,31,32,36,39,41,43) \quad$ Juxtafacet cysts are thought to form as a result of arthrotic disruption of the facet joint, leading to degenerative spondylolisthesis. ${ }^{12)}$ Unlike ganglion cysts, synovial cysts are connected to the facet joint and contain a synovial lining. ${ }^{28)}$ However, differentiation of these two types of cysts is difficult based only on neurological imaging. ${ }^{16)}$ Most juxtafacet cysts occur in the lumbar spine, and contribute significantly to narrowing of the spinal canal, and lateral thecal sac and nerve root compression. ${ }^{16,21)}$

The present study retrospectively reviewed the age and sex distribution, preoperative symptoms, neuroimaging findings, and surgical outcomes of 10

Received October 3, 2006; Accepted April 6, 2007 resections of juxtafacet cysts in nine patients, and assessed the relationship between surgical method and progression of spinal spondylolisthesis or cyst recurrence.

\section{Patients and Methods}

The clinical records were retrospectively reviewed of nine patients with 10 lumbar juxtafacet cysts who underwent 10 resections in our institution between 1998 and 2006. No patient had sustained traumatic injury inducing spinal instability. Cases 4 and 10 occurred in the same patient who underwent further resection when a new juxtafacet cyst arose in another region. Patient characteristics including age, sex, preoperative symptoms, neuroimaging findings, surgical techniques, and outcomes were investigated. Lateral roentgenography in standing dynamic motion was used to estimate the slip angle, that is, the percentage slip of spondylolisthesis according to the previously proposed scale. ${ }^{45}$ The degree of facet joint osteoarthritis at the cyst level 

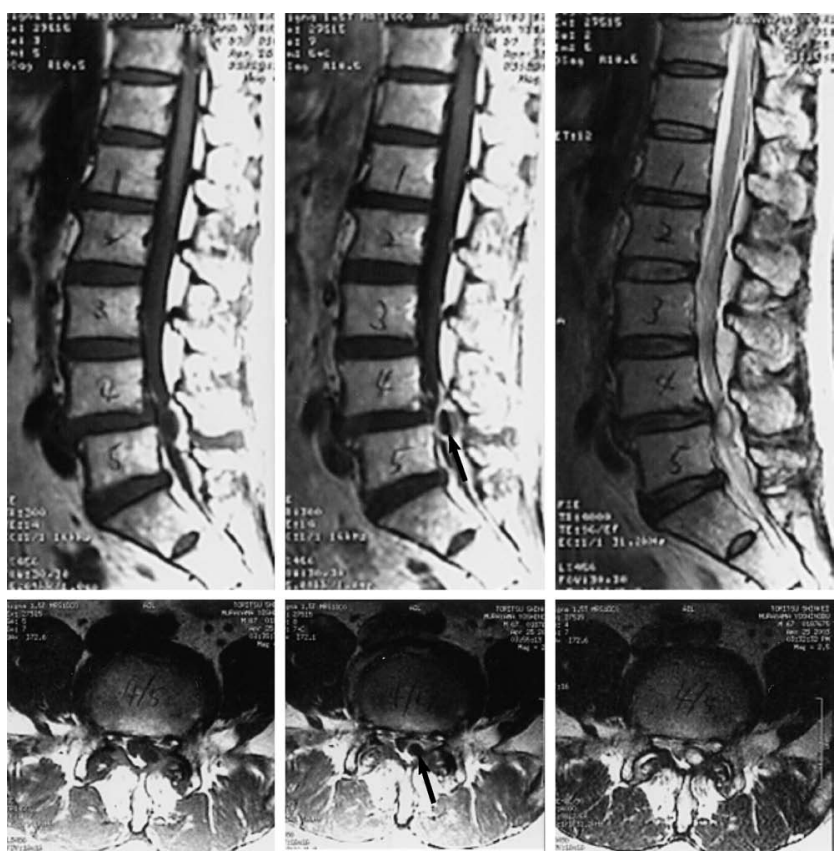

Fig. 1 Case 5. Sagittal (upper row) and axial (lower row) $\mathrm{T}_{1}$-weighted (left column), $\mathrm{T}_{1^{-}}$ weighted with gadolinium (center column), and $\mathrm{T}_{2}$-weighted (right column) magnetic resonance images showing a left L4-5 synovial cyst arising from the adjacent facet joint with a distinct boundary and ring enhancement (arrow), and mild spondylolisthesis at the same spinal level.

was estimated by computed tomography and graded according to the following scale ${ }^{11)}$ : 0 , normal; 1 , slight narrowing of the joint space \pm small osteophytes/hypertrophy; 2 , slight to moderate narrowing of the joint space \pm osteophytes/hypertrophy \pm subarticular erosions; and 3 , severe narrowing of the joint space \pm large osteophytes \pm subarticular cysts or severe erosions \pm listhesis. Outcome after surgery was graded according to the following scale ${ }^{37)}$ : excellent, no further discomfort and return to full recovery; good, normal neurological examination with minimal back or leg pain; and poor, frequent back or leg pain with limitation of daily activity and/or neurological deficit.

\section{Results}

Table 1 summarizes the clinical characteristics of the 10 cases of juxtafacet cyst treated by surgical excision. The patients were aged 53 to 88 years (mean 65.4 years). The pre-existing conditions were cerebral palsy (Case 3), Parkinson's disease (Case 9), and diabetes (Case 4/10). Most of the symptoms
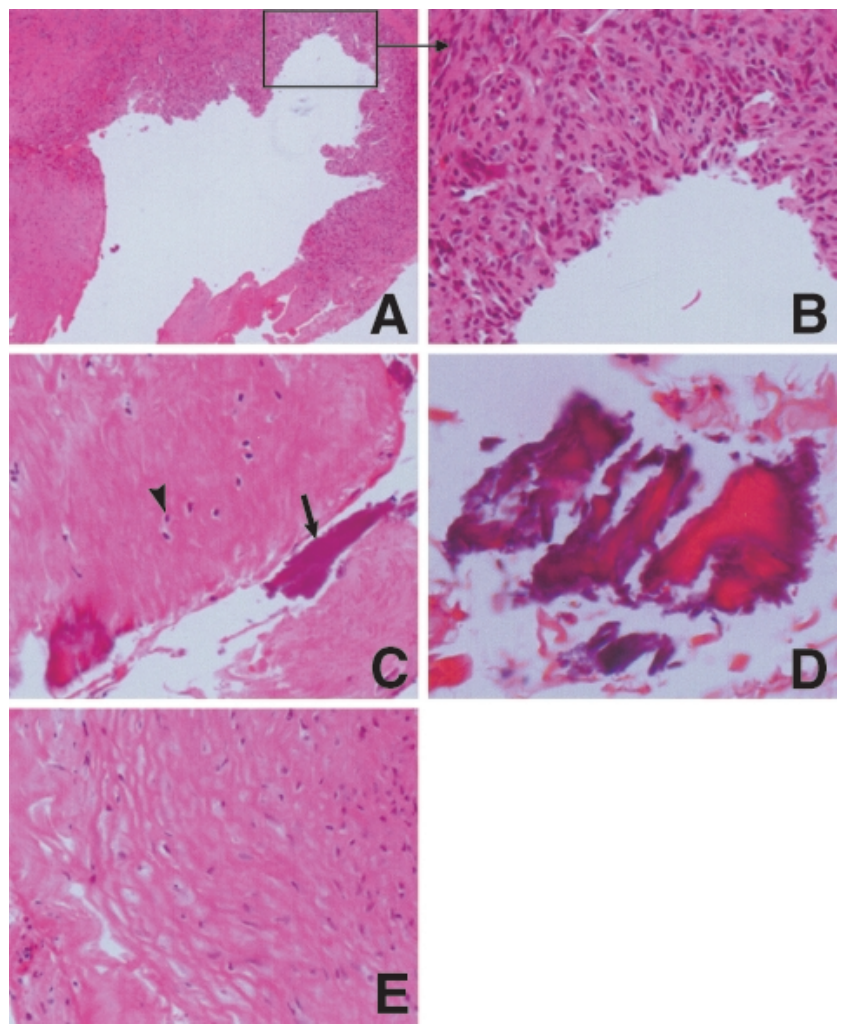

Fig. 2 Photomicrographs of a synovial cyst specimen showing cyst wall and myxoid degeneration (A: hematoxylin and eosin [HE] stain, $\times 4$ ), synovial lining with stratified columnar epithelium (B, magnified section indicated in A: HE stain, $\times 10$ ), calcification (arrow) and cartilage degeneration (arrowhead) of the cyst wall (C: HE stain, $\times 20$ ), bony tissue component (D: HE stain, $\times 20$ ), and variable numbers of fibroblasts and inflammatory cells within thick fibrous tissue (E: HE stain, $\times 20$ ).

reflected the anatomic location of the juxtafacet cyst and the level of resultant maximal lumbar stenosis. The most common preoperative symptoms were pain and radiculopathy of the lower extremities, affecting all patients, followed by motor weakness of the lower extremities ( $n=5$ ), sensory disturbance ( $n$ $=4)$, and back pain $(n=4)$. Neurogenic claudication was present in four patients; walking distance was limited to $200 \mathrm{~m}$ in two of these patients, to 100 $m$ in one, and the other was unable to walk unaided. Cauda equina syndrome and myelopathy were not observed.

Cysts were most commonly located at L4-5 facet joint, the most mobile segment, in seven patients, followed by L2-3 in two and L5-S1 in one (Table 1). Degenerative spondylolisthesis was radiologically confirmed as the precursor to arthrotic disruption of 
Table 1 Characteristics of 10 patients who underwent surgical excision of juxtafacet cyst

\begin{tabular}{|c|c|c|c|c|c|}
\hline $\begin{array}{l}\text { Case } \\
\text { No. }\end{array}$ & $\begin{array}{c}\text { Age } \\
\text { (yrs)/ } \\
\text { Sex }\end{array}$ & Symptoms & $\begin{array}{l}\text { Cyst level/ } \\
\text { Side }\end{array}$ & $\begin{array}{c}\text { Size } \\
(\mathrm{mm})\end{array}$ & $\begin{array}{l}\text { MR imaging } \\
\left(\mathrm{T}_{1} / \mathrm{T}_{2} / \mathrm{Gd}\right)\end{array}$ \\
\hline 2 & $73 / \mathrm{M}$ & $\begin{array}{l}\text { dysesthesia, leg pain, motor weakness, } \\
\text { intermittent claudication }\end{array}$ & $\mathrm{L} 4-5 / \mathrm{rt}$ & 10 & iso/high/NP \\
\hline 3 & $53 / \mathrm{F}$ & $\begin{array}{l}\text { lumbago, dysesthesia, leg pain, motor weakness, } \\
\text { sensory disturbance }\end{array}$ & L4-5/rt & 4 & iso/high/NP \\
\hline 5 & $62 / \mathrm{M}$ & $\begin{array}{l}\text { dysesthesia, leg pain, motor weakness, } \\
\text { intermittent claudication }\end{array}$ & L4-5/lt & 12 & low/high/ + \\
\hline 6 & $63 / \mathrm{M}$ & $\begin{array}{l}\text { lumbago, dysesthesia, leg pain, } \\
\text { intermittent claudication }\end{array}$ & L5-S1/lt & 10 & iso/low/NP \\
\hline 7 & $55 / \mathrm{M}$ & dysesthesia, leg pain, sensory disturbance & L4-5/lt & 8 & iso/high/ + \\
\hline 8 & $69 / \mathrm{M}$ & $\begin{array}{l}\text { dysesthesia, leg pain, motor weakness, } \\
\text { sensory disturbance }\end{array}$ & $\mathrm{L} 2-3 / \mathrm{rt}$ & 4 & iso/high/NP \\
\hline
\end{tabular}

the facet joint in four patients, and the vast majority of the patients exhibited grade 1 disease (Meyerding classification $^{30}$ ). The mean percentage slip in the patients with degenerative spondylolisthesis was $12.5 \pm 7.3 \%$ (range $0-18.6 \%$ ) in extension and $15.7 \pm 5.9 \%(6.0-21.7 \%)$ in flexion. The average slip angle was $-11.4 \pm 5.6^{\circ}$ (from $-3^{\circ}$ to $-23^{\circ}$ ) in extension and $-4.5 \pm 5.5^{\circ}$ (from $+5^{\circ}$ to $-17^{\circ}$ ) in flexion, so the difference between extension and flexion was $6.9 \pm 2.7^{\circ}$ (range $3-13^{\circ}$ ). Facet joint osteoarthritis at the cyst level was grade 0 in two cases, grade 1 in one, grade 2 in six, and grade 3 in one. $\mathrm{T}_{1}$-weighted magnetic resonance (MR) imaging showed seven of the 10 cysts as isointense and three as hypointense. Administration of gadoliniumdiethylenetriaminepenta-acetic acid caused enhancement in four of the four cysts (Fig. 1). $\mathrm{T}_{2}$-weighted MR imaging showed six lesions as hyperintense, three as hypointense, and one as isointense. Mean maximum cyst diameter was $9.9 \mathrm{~mm}$ (range 4 to 20 $\mathrm{mm}$ ). Five cysts were located on the right and five on the left of the spine.

All patients underwent bilateral total $(n=6)$ or partial laminectomy $(\mathrm{n}=4)$, with $(\mathrm{n}=3)$ or without $(\mathrm{n}=7)$ facetectomy, combined with gross total $(\mathrm{n}=8)$ or partial $(\mathrm{n}=2)$ cyst resection without concomitant fusion (Table 1). In all three cases of medial facetectomy, part of the facet joint was removed as the cyst extended into the joint. A mass of compressed tissue attached to the facet joint was found in all cases. Histological diagnosis confirmed the diagnosis of juxtafacet cyst in all cases. As the state of the pathology specimen depended on the extraction method (piecemeal resection vs. en-bloc resection), the specimens could not be compared in the same way. Proliferation of synovial lining with stratified columnar epithelium was found in only two cases (Fig. 2A, B), with calcification in eight, evidence of cartilage degeneration of the cyst wall in six (Fig. 2C), and bony component in four (Fig. 2D). Varying degrees of fibroblast and inflammatory cell infiltration were observed within the thick fibrous tissue in all cases (Fig. 2E). No surgical complications such as cerebrospinal fluid leakage, hematoma, or infection were observed.

Good relief of preoperative painful radiculopathy was obtained in all patients soon after surgery. Preoperative motor weakness and/or sensory disturbance also improved in all patients within 2 weeks postoperatively. Neurogenic claudication normalized completely within 2 weeks in three of the four patients, and the patient who could not walk unaided was able to walk $20 \mathrm{~m}$ after 1 month of postoperative rehabilitation. Lumbago improved within 1 month in three of the four patients.

All patients were followed up as outpatients with neurology and radiology examinations such as radiography and $M R$ imaging to confirm the postoperative progression of spinal spondylolisthesis or cyst recurrence. The follow-up period has continued for 20 to 124 months (mean 52.1 months) from the day of surgery to September 2006 (Table 1). Outcome was excellent in seven patients and good in two. Poor outcome was observed in one patient (Case 4) who underwent initial cystectomy at the left L4-5 facet joint and had good relief of preoperative 
Table 1, continued

\begin{tabular}{|c|c|c|c|c|}
\hline $\begin{array}{l}\text { Facet joint } \\
\text { osteoarthritis } \\
\text { (grade) }^{*}\end{array}$ & $\begin{array}{l}\text { Spondylolisthesis } \\
\text { (\% slip, E/F) }\end{array}$ & $\begin{array}{c}\text { Slip angle } \\
\left({ }^{\circ}, \mathrm{E} / \mathrm{F} / / \mathrm{F}-\mathrm{E}\right)^{* *}\end{array}$ & Surgery & $\begin{array}{l}\text { Postoperative follow up } \\
\text { (mos)/Outcome }\end{array}$ \\
\hline 2 & $-(0 / 0)$ & $-7 /-3 / / 4$ & L4-5 total LN/facetec(+ )/TR & 124/excellent \\
\hline 2 & $+(15.2 / 21.7)$ & $-15 /-2 / / 13$ & L4-5 total LN/facetec(-)/TR & 108/good \\
\hline 0 & $+(0 / 6)$ & $-10 /-4 / / 6$ & L-4 partial LN/facetec( + )/TR & 105/excellent \\
\hline 1 & $+(18.6 / 18.6)$ & $-5 /+5 / / 10$ & L4-5 total LN/facetec( - )/TR & 39/excellent \\
\hline 3 & $-(0 / 0)$ & $-16 /-9 / / 7$ & L5-S1 partial LN/facetec(-)/TR & 22/excellent ${ }^{\dagger}$ \\
\hline 2 & $+(16.3 / 16.3)$ & $-23 /-17 / / 6$ & L-4 partial LN/facetec( - )/TR & 21/excellent \\
\hline 0 & $-(0 / 0)$ & $-9 /-3 / / 6$ & L-2 total LN/facetec(-)/TR & 21/excellent \\
\hline
\end{tabular}

* Degree of facet joint osteoarthritis at the cyst level estimated by computed tomography and graded according to Doyle and Merrilees. ${ }^{11)}{ }^{* *}$ Slip angle at the cyst level estimated by lateral roentgenography in standing dynamic motion according to White and Panjabi. ${ }^{45)} * * *$ Cases 4 and 10 were the same patient who underwent staged surgeries. Nine months after the initial cystectomy at the left L4-5 facet joint, a new cyst occurred on the opposite side of the same spinal segment, and was removed after 21 months. ${ }^{\dagger}$ Case 6 had undergone cystectomy at the left L5-S1 facet joint. Five months postoperatively, a new cyst occurred at the right L4-5 facet joint, and was followed up conservatively. E: extension position, F: flexion position, facetec: facetectomy, LN: laminectomy, MR: magnetic resonance, NP: not performed, PR: partial removal, TR: gross total removal.

leg pain and dysesthesia. However, pain in the contralateral leg occurred after 9 months, and MR imaging revealed a new juxtafacet cyst at the right L4-5 facet joint. Juxtafacet cyst later occurred in a new location in Cases 4 and 6. Neither of these patients had demonstrated spondylolisthesis on preoperative radiological studies. Case 4 underwent a second resection to remove the cyst 21 months after the initial surgery. Case 6 underwent cystectomy at the left L5-S1 facet joint, but the second cyst radiologically confirmed 5 months postoperatively at the right L4-5 facet joint remained asymptomatic, and was followed conservatively (Fig. 3). None of the patients have developed symptomatic spondylolisthesis or required subsequent fusion to date.

\section{Discussion}

Repeated microtrauma at areas of spinal segmental instability associated with facet joint osteoarthritis is thought to be important in the pathogenesis of juxtafacet cyst. ${ }^{4,8,11,38)}$ The resulting defect in the intervertebral joint capsule becomes surrounded by myxoid degeneration and cyst formation in the collagenous connective tissue. ${ }^{15,18,20,40)}$ Fibroblasts are also thought to excrete increased amounts of hyaluronic acid in response to repeated stress. ${ }^{15,41)}$ The common finding is degenerative change with proliferation of reactive and inflammatory cells, including synovial cells, and formation of a cystic cavity, ${ }^{26)}$ which can communicate with the joint. ${ }^{21}$

The L4-5 segment, which has the greatest range of motion in the lumbar spine, is the most common location with $51-68 \%$ of juxtafacet cysts occurring at this location. ${ }^{6,22,28)}$ In the present series, seven of the 10 cysts occurred at the L4-5 facet joint. The mean age of the patients in our series was 65.4 years, very similar to another series of 440 patients with mean age of approximately 65 years. ${ }^{12)}$

A history of traumatic injury has been documented in around $12 \%$ of cases of synovial cyst, ${ }^{28)}$ but in none of the present patients. Most synovial cysts originate from the intervertebral facet joint, and extend to the posterior-lateral side of the lumbar canal, but also originate from the yellow ligament, ${ }^{1,3,4,31,42,44)}$ anterior longitudinal ligament, ${ }^{2)}$ posterior longitudinal ligament, ${ }^{5,27}$ and ligamentum interspinale. ${ }^{33)}$ Juxtafacet cysts are known to complicate spondylolisthesis as a result of the associated partial destruction of intervertebral joints. ${ }^{28)}$ Coexisting spondylolisthesis was present in four of our 10 cases, and comparable to the frequency of $32 \%$ 

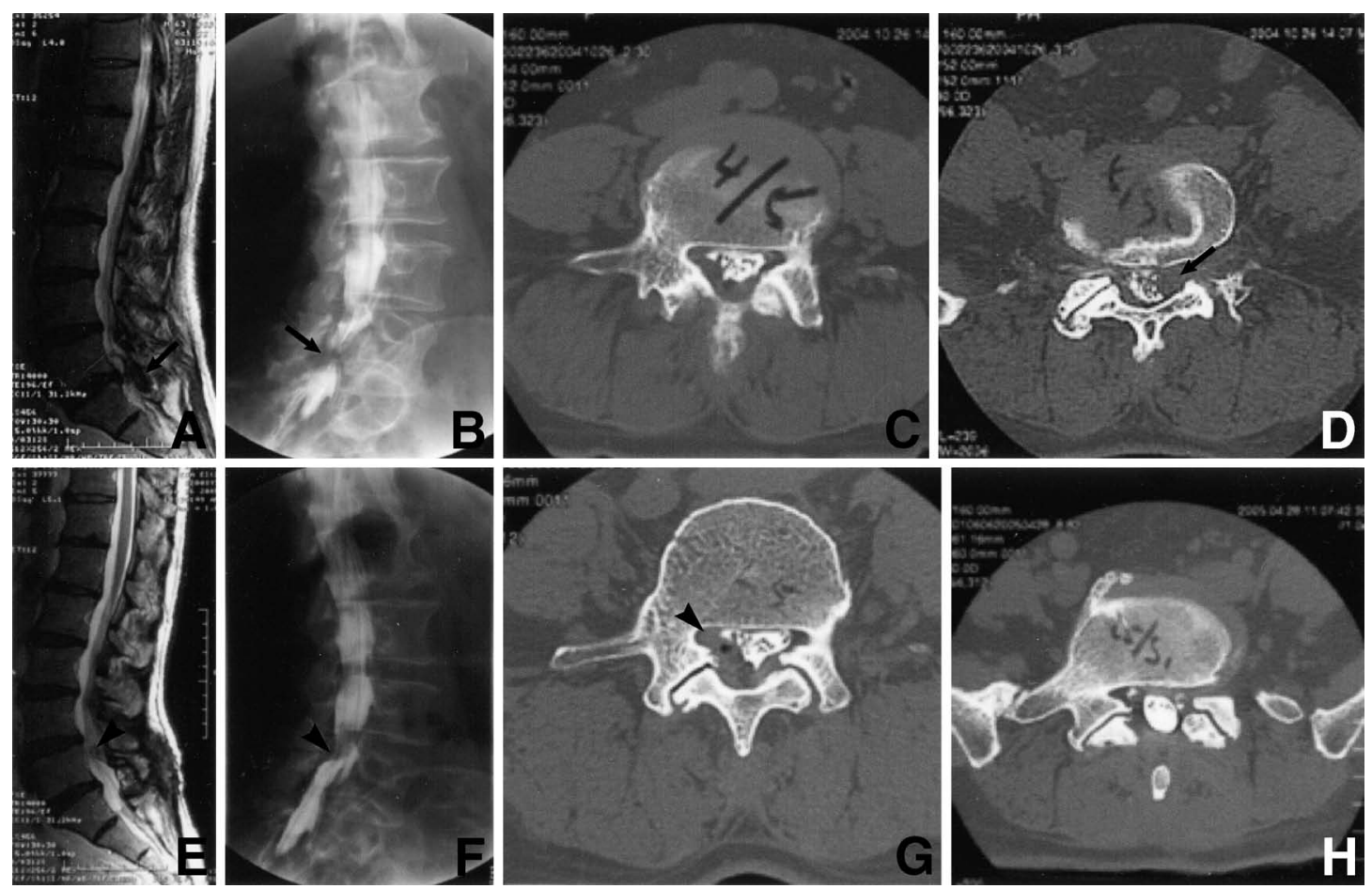

Fig. 3 Case 6. Sagittal $T_{2}$-weighted magnetic resonance images (A, E), myelograms (B, F), and computed tomography myelograms (C, G: at L4-5; D, H: at L5-S1), revealing an abnormal mass attached to the left L5-S1 facet joint (arrow) (A-D), and 5 months postoperatively showing expansion of the dural sac previously compressed by the left L5-S1 cyst, and a new abnormal mass attached to the right L4-5 facet joint (arrowhead) (E-H).

Table 2 Review of reported series showing varying ratio of development of postoperative spinal instability and recurrence of lumbar synovial cyst

\begin{tabular}{lcccccc}
\hline Author (Year) & $\begin{array}{c}\text { No. of } \\
\text { cases }\end{array}$ & $\begin{array}{c}\text { No. of } \\
\text { spondylolisthesis } \\
(\%)\end{array}$ & $\begin{array}{c}\text { No. of } \\
\text { concomitant } \\
\text { spinal } \\
\text { fixation (\%) }\end{array}$ & $\begin{array}{c}\text { Mean } \\
\text { follow-up } \\
\text { duration } \\
\text { (mos) }\end{array}$ & $\begin{array}{c}\text { No. of } \\
\text { recurrences } \\
\text { of cyst (\%) }\end{array}$ & $\begin{array}{c}\text { No. of } \\
\text { advances of } \\
\text { spondylolisthesis } \\
(\%)\end{array}$ \\
\hline $\begin{array}{c}\text { Onofrio and Mih } \\
(1988)^{34)}\end{array}$ & 12 & $8(66.7)$ & 0 & 34 & 0 & $2(16.7)$ \\
$\begin{array}{c}\text { Freidberg et al. } \\
(1994)^{16)}\end{array}$ & 23 & NA & 0 & NA & NA & $1(4.3)$ \\
$\begin{array}{l}\text { Sabo et al. } \\
(1996)^{37)}\end{array}$ & 60 & $15(25)$ & $7(11.7)$ & 12 & $4(6.7)^{*}$ & $2(3.3)$ \\
$\begin{array}{c}\text { Lyons et al. } \\
(2000)^{28)}\end{array}$ & 194 & $74(38.1)$ & $18(9.3)$ & 26 & $3(1.5)^{* *}$ & $4(2.1)$ \\
$\begin{array}{c}\text { Sandhu et al. } \\
(2004)^{39)}\end{array}$ & 17 & $8(47)$ & 0 & 13 & NA & NA \\
$\begin{array}{c}\text { Khan et al. } \\
(2005)^{24)}\end{array}$ & 39 & $32(82.1)$ & $26(66.7)$ & NA & $1(2.6)^{* * *}$ & NA \\
Present series & 10 & $4(40)$ & 0 & 16 & $2(20)^{\dagger}$ & 0 \\
\hline
\end{tabular}

*Three patients developed asynchronous cyst at the same level but contralateral to the previous cyst. One patient developed recurrent cyst at the same location. ${ }^{* *}$ Three patients developed asynchronous cyst at the same site and were treated conservatively. ${ }^{* * *}$ One patient had recurrence at the site of surgery approximately 5 years after initial surgery. ${ }^{\dagger}$ Two patients exhibited new, asynchronous synovial cyst after 5 and 9 months, contralateral to the initial lesion. NA: not applicable. 
previously reported..$^{6,43)}$

Surgery should be performed if conservative treatment is ineffective for juxtafacet cyst. $4,7,29,35)$ Cysts tend to occur at the segment with greatest motion, so the resultant increased stress is probably a predisposing factor in the development of juxtafacet cysts. ${ }^{28)}$ Accordingly, less invasive surgery, such as small laminectomy with minimal removal of the facet joint, may be required to prevent postoperative joint instability. ${ }^{9)}$ Our patients all underwent bilateral laminectomy without facetectomy. Of course, unilateral partial hemilaminectomy using microsurgical techniques may be adequate for some juxtafacet cysts. The advantage of the unilateral approach is that only a minimal amount of paravertebral muscles must be detached, and only on one side and not both as in bilateral laminectomy. However, we performed bilateral laminectomy even for unilateral cysts, because most cysts had expanded over and under the intervertebral joint. Moreover, these cysts were fibrous, tough, and densely attached to the dura mater. ${ }^{37)}$ Therefore, cysts were extracted from both sides unless dural violation or root injury was found, to secure a wide operative field. Immediate good relief of radiculopathy and neurogenic claudication was obtained in all patients.

Concomitant spinal fixation does not clearly have any impact on cyst recurrence or progression of spondylolisthesis (Table 2). ${ }^{16,24,28,34,37,39)}$ A comparatively high rate of concomitant spinal fixation $(26$ of 39 cases) resulted in only one instance of cyst recurrence. ${ }^{24)}$ On the other hand, cyst extraction without fixation in 12 patients, eight also with spondylolisthesis, resulted in no cyst recurrence. ${ }^{34)}$ Cysts were removed without fixation in 23 cases, with progression of spondylolisthesis in $4.3 \% .{ }^{16)}$ However, concomitant spinal fixation in seven of 60 patients $(11.7 \%)^{37)}$ and 18 of 194 patients $(9.3 \%)^{28)}$ resulted in spondylolisthesis in $3.3 \%$ and $2.1 \%$, respectively.

The progression to spondylolisthesis was not observed before a mean of 52.1 months in the present series. However, new synovial cysts developed in two patients, contralateral to the original cyst at the same and different levels, after 5 and 9 months. Asynchronous cysts were found on the contralateral side in three of 26 cases of resected juxtafacet cysts at 6,11 , and 14 months postoperatively. ${ }^{37)}$ Asynchronous cyst appeared 6 months after cyst resection, at the same level but on the opposite side. ${ }^{14)}$ Therefore, new cysts tend to appear on the contralateral side about 6 months to 1 year after cyst resection, possibly because surgery altered the forces acting on the intervertebral joint, causing increased stress on the contralateral side, inducing collapse of the contralateral facet joint and formation of a new juxtafacet cyst. Surgeons should exercise individual judgment about the necessity for concomitant spinal fixation, based on factors such as cyst size, involvement of surrounding structures, degree of preoperative spondylolisthesis, and facet joint destruction. ${ }^{28)}$ Postoperative follow up is important for patients undergoing cyst decompression without fixation to limit the risk of new olisthy or spondylolisthesis.

Surgical removal of juxtafacet cysts is a safe and effective treatment providing symptomatic relief. The wide operative field acquired by bilateral laminectomy helps to ensure safe and easy resection of cysts from multiple directions. The indications for concomitant spinal fixation are based on cyst size, involvement of surrounding structures, degree of preoperative spondylolisthesis, and facet joint destruction to prevent progression of spinal spondylolisthesis or cyst recurrence.

\section{References}

1) Abdullah AF, Chambers RW, Daut DP: Lumbar nerve root compression by synovial cysts of the ligamentum flavum. Report of four cases. J Neurosurg 60: 617-620, 1984

2) Alguacil-Garcia A: Spinal synovial cyst (ganglion). Review and report of a case presenting as a retropharyngeal mass. Am J Surg Pathol 11: 732-735, 1987

3) Asamoto S, Jimbo H, Fukui Y, Doi H, Sakagawa H, Ida $M$, Takahashi $M$, Shiraishi $N$ : Cyst of the ligamentum flavum - case report. Neurol Med Chir (Tokyo) 45: 653-656, 2005

4) Azzam CJ: Midline lumbar ganglion/synovial cyst mimicking an epidural tumor: case report and review of pathogenesis. Neurosurgery 23: 232-234, 1988

5) Baba H, Furusawa N, Maezawa Y, Uchida K, Kokubo Y, Imura S, Noriki S: Ganglion cyst of the posterior longitudinal ligament causing lumbar radiculopathy: case report. Spinal Cord 35: 632-635, 1997

6) Banning CS, Thorell WE, Leibrock LG: Patient outcome after resection of lumbar juxtafacet cysts. Spine 26: 969-972, 2001

7) Bjorkengren AG, Kurz LT, Resnick D, Sartoris DJ, Garfin SR: Symptomatic intraspinal synovial cysts: opacification and treatment by percutaneous injection. AJR Am J Roentgenol 149: 105-107, 1987

8) Cameron SE, Hanscom DA: Rapid development of a spinal synovial cyst. A case report. Spine 17: 1528-1530, 1992

9) Charest DR, Kenny BG: Radicular pain caused by synovial cyst: an underdiagnosed entity in the elderly? J Neurosurg 92: 57-60, 2000

10) Cipri S, Cafarelli F, Ielo A, Gambardella G: Microsurgical approach to lumbar synovial cysts. Technical notes. J Neurosurg Sci 48: 29-36, 2004

11) Doyle AJ, Merrilees M: Synovial cysts of the lumbar facet joints in a symptomatic population: prevalence 
on magnetic resonance imaging. Spine 29: 874-878, 2004

12) Epstein NE: Lumbar synovial cysts: a review of diagnosis, surgical management, and outcome assessment. J Spinal Disord Tech 17: 321-325, 2004

13) Farrokh D: Lumbar intraspinal synovial cysts of different etiologies: Diagnosis by CT and MR imaging. J Belge Radiol 81: 275-278, 1998

14) Finkelstein SD, Sayegh R, Watson P, Knuckey N: Juxta-facet cysts. Report of two cases and review of clinicopathologic features. Spine 18: 779-782, 1993

15) Franck JI, King RB, Petro GR, Kanzer MD: A posttraumatic lumbar spinal synovial cyst. Case report. J Neurosurg 66: 293-296, 1987

16) Freidberg SR, Fellows T, Thomas CB, Mancall AC: Experience with symptomatic spinal epidural cysts. Neurosurgery 34: 989-993, 1994

17) Fritz RC, Kaiser JA, White AH, De Long WB, Gamburd RS: Magnetic resonance imaging of a thoracic intraspinal synovial cyst. Spine 19: 487-490, 1994

18) Gorey MT, Hyman RA, Black KS, Scuderi DM, Cinnamon J, Kim KS: Lumbar synovial cysts eroding bone. AJNR Am J Neuroradiol 13: 161-163, 1992

19) Hemminghytt S, Daniels DL, Williams AL, Haughton VM: Intraspinal synovial cysts: natural history and diagnosis by CT. Radiology 145: 375-376, 1982

20) Holtzman RN, Dubin R, Yang WC, Rorat E, Liu HM, Leeds NE: Bilateral symptomatic intraspinal T12-L1 synovial cysts. Surg Neurol 28: 225-230, 1987

21) Howington JU, Connolly ES, Voorhies RM: Intraspinal synovial cysts. 10-year experience at the Ochsner Clinic. J Neurosurg 91: 193-199, 1999

22) Hsu KY, Zucherman JF, Shea WJ, Jeffrey RA: Lumbar intraspinal synovial and ganglion cysts (facet cysts). Ten-year experience in evaluation and treatment. Spine 20: 80-89, 1995

23) Kao CC, Winkler SS, Turner JH: Synovial cyst of spinal facet. Case report. J Neurosurg 41: 372-376, 1974

24) Khan AM, Synnot K, Cammisa FP, Girardi FP: Lumbar synovial cysts of the spine: an evaluation of surgical outcome. J Spinal Disord Tech 18: 127-131, 2005

25) Koga H, Yone K, Yamamoto T, Komiya S: Percutaneous CT-guided puncture and steroid injection for the treatment of lumbar discal cyst: a case report. Spine 28: E212-216, 2003

26) Kurz LT, Garfin SR, Unger AS, Thorne RP, Rothman RH: Intraspinal synovial cyst causing sciatica. J Bone Joint Surg Am 67: 865-871, 1985

27) Lin RM, Wey KL, Tzeng CC: Gas-containing "ganglion" cyst of lumbar posterior longitudinal ligament at L3. Case report. Spine 18: 2528-2532, 1993

28) Lyons MK, Atkinson JL, Wharen RE, Deen HG, Zimmerman RS, Lemens SM: Surgical evaluation and management of lumbar synovial cysts: the Mayo Clinic experience. J Neurosurg 93(1 Suppl): 53-57, 2000

29) Maezawa Y, Baba H, Uchida K, Furusawa N, Kubota C, Yoshizawa K: Spontaneous remission of a solitary intraspinal synovial cyst of the lumbar spine. Eur Spine J 9: 85-87, 2000

30) Meyerding H: Spondylolisthesis. Surg Gynecol Obstet 54: 371-377, 1932

31) Mizuno J, Nakagawa $H$, Inoue $T$, Hashizume $Y$ :
Ligamentum flavum hematoma in the lumbar spine. Neurol Med Chir (Tokyo) 45: 212-215, 2005

32) Nakayama S, Fujino H, Inomori S, Shuto T, Basugi N, Kuwabara T: [A case of a lumbar spinal synovial cyst located on the midline]. No Shinkei Geka 26: 717-722, 1988 (Jpn, with Eng abstract)

33) Ogawa Y, Kumano K, Hirabayashi S, Aota Y: A ganglion cyst in the lumbar spinal canal. A case report. Spine 17: 1429-1431, 1992

34) Onofrio BM, Mih AD: Synovial cysts of the spine. Neurosurgery 22: 642-647, 1988

35) Parlier-Cuau C, Wybier M, Nizard R, Champsaur P, Le Hir P, Laredo JD: Symptomatic lumbar facet joint synovial cysts: clinical assessment of facet joint steroid injection after 1 and 6 months and long-term follow-up in 30 patients. Radiology 210: 509-513, 1999

36) Reddy P, Satyanarayana S, Nanda A: Synovial cyst of lumbar spine presenting as disc disease: a case report and review of literature. J La State Med Soc 152: 563-566, 2000

37) Sabo RA, Tracy PT, Weinger JM: A series of 60 juxtafacet cysts: clinical presentation, the role of spinal instability, and treatment. J Neurosurg 85: 560-565, 1996

38) Salcman M, Khan A, Symonds DA: Calcium pyrophosphate arthropathy of the spine: case report and review of the literature. Neurosurgery 34: 915-918, 1994

39) Sandhu FA, Santiago P, Fessler RG, Palmer S: Minimally invasive surgical treatment of lumbar synovial cysts. Neurosurgery 54: 107-112, 2004

40) Schelfaut P, Van Holsbeeck B, Mortelmans L: Synovial cyst of the lumbar spine. A case report. J Belge Radiol 72: 373-376, 1989

41) Sze CI, Kindt G, Huffer WB, Chang M, Wang M, Kleinschmidt-De Masters BK: Synovial excrescences and cysts of the spine: clinicopathological features and contributions to spinal stenosis. Clin Neuropathol 23: 80-90, 2004

42) Takano Y, Homma T, Okumura H, Takahashi HE: Ganglion cyst occurring in the ligamentum flavum of the cervical spine. A case report. Spine 17: 1531-1533, 1992

43) Trummer M, Flaschka G, Tillich M, Homann CN, Unger F, Eustacchio S: Diagnosis and surgical management of intraspinal synovial cysts: report of 19 cases. J Neurol Neurosurg Psychiatry 70: 74-77, 2001

44) Vernet O, Fankhauser H, Schnyder P, Deruaz JP: Cyst of the ligamentum flavum: report of six cases. Neurosurgery 29: 277-283, 1991

45) White AA, Panjabi MM: Clinical Biomechanics of the Spine, ed 2. Philadelphia, JB Lippincott, 1990, 752 pp

Address reprint requests to: Tohru Terao, M.D., Department of Neurosurgery, Tokyo Metropolitan Neurological Hospital, 2-6-1 Musashidai, Fuchu, Tokyo 183-0042, Japan.

e-mail: tohru@jg7.so-net.ne.jp 


\section{Commentary}

Juxtafacet and/or synovial cysts can now be identified with neuroimaging. First the CT and now MRI allow us to know preoperatively the pathology. Occasionally, they are found with back pain symptoms only and such cases are treated medically. Operative intervention is needed with progressive or very lax spondylolisthesis. Most cases, as described in this report, have significant radiculopathy.

Removing the cyst does relieve the radiculopathic sciatic-like pain. If the pathology and symptoms are very unilateral, total resection of the lesion is all that is needed.

But we are doing segmental fixation fusions in more and more cases. Flexion-extension x-rays are done. If there is significant movement of $4 \mathrm{~mm}$ or more, or if the subluxation is greater than $8-10 \mathrm{~mm}$ on any film, we do a fusion with the primary procedure. In this report, 2 of 10 cases (or 20\%) required repeat decompressions and fusions in follow up. We try to identify those cases preoperatively.

Incidentally, in many of our deformity cases of degenerative scoliosis, we are finding more and more synovial cysts - some in the canal and some posterior-lateral outside the canal. With deformity correction surgery, we remove these cysts and drill out the joint for fusions.

The authors have done a nice review. And the discussion is fair and balanced. Our practice patterns are very similar with the minor exception of carrying out a few more fusions initially.

Thomas B. DuCKER, M.D., F.A.C.S. Department of Neurosurgery Johns Hopkins University Annapolis, Maryland, U.S.A.

Terao et al. report a retrospective but instructive analysis of symptomatic juxtafacet cysts of 10 patients with a good review in the discussion. As they mentioned, it is described "juxtafacet cysts" or "synovial cyst." As the authors pointed out, they performed bilateral laminectomy for all of their patients even unilateral cysts. Because of high percentage of coexisting spondylolisthesis, unilateral laminectomy may be better as a minimum invasive surgery.

In the discussion, it is interesting that new cyst was found on the contralateral side in three out of 26 cases of resected juxtafacet cyst about 6 months to 1 year after the first surgery. We have to keep it in mind in our outpatient clinic after the surgery.

Recently we neurosurgeons take care of lumbar disease patients much more than before. Therefore we should know this entity and its surgical managements.

Yoshinobu IWASAKI, M.D. Department of Neurosurgery

Hokkaido University Graduate School of Medicine Sapporo, Japan
The article by Drs. Terao, Takahashi, Taniguchi, Ide, Shinozaki, Nakauchi, and Kubota presents a study of 10 patients after resection of juxtafacet cysts. The work seeks to clarify the relationship between the juxtafacet cyst and the presence of indicators of mechanical instability, such as percentage slip of spondylolisthesis, and the degree of facet joint osteoarthritis. The analysis is retrospective, covering a span of approximately 8 years (1998-2006).

The natural history of juxtafacet cysts is not clearly understood. ${ }^{1,4)}$ However, it is believed that spinal instability gives rise to the juxtafacet cysts. Many authors note that the term juxtafacet cyst itself is controversial in term of histological classification, if not in clinical management. ${ }^{1-6)}$ That being noted, the surgical treatment of these cysts, especially in cases of radiculopathy is supported. Terao et al. follow clinical outcome as well, with good outcomes.

This is a high-quality, well-documented, early study. With this first group of 10 patients showing that a longer-term study has value, we would now encourage continuation of this promising work, to enable the power to make conclusions regarding the utility of their classification system. Overall, the work is interesting and will increase in power should the authors continue their study and include additional subjects.

\section{References}

1) Banning CS, Thorell WE, Leibrock LG: Patient outcome after resection of lumbar juxtafacet cysts. Spine 26: 969-972, 2001

2) Choudhri HF, Perling LH: Diagnosis and management of juxtafacet cysts. Neurosurg Focus 20: E1, 2006

3) Christophis P, Asamoto S, Kuchelmeister K, Schachenmayr W: "Juxtafacet cysts", a misleading name for cystic formations of mobile spine (CYFMOS). Eur Spine J 2007; Epub 2007 Jan 4

4) Khan AM, Girardi F: Spinal lumbar synovial cysts. Diagnosis and management challenge. Eur Spine J 15: 1176-1182, 2006

5) Kusakabe T, Kasama F, Aizawa T, Sato T, Kokubun S: Facet cyst in the lumbar spine: radiological and histopathological findings and possible pathogenesis. J Neurosurg Spine 5: 398-403, 2006

6) Salmon B, Martin D, Lenelle J, Stevenaert A: Juxtafacet cyst of the lumbar spine. Clinical, radiological and therapeutic aspects in 28 cases. Acta Neurochir (Wien) 143: 129-134, 2001

Howard LEVENE, M.D. and Christopher M. LofTus, M.D., D.H.C. (Hon.), F.A.C.S. Department of Neurosurgery Temple University School of Medicine Philadelphia, Pennsylvania, U.S.A. 